\title{
PENGGUNAAN PERMAINAN PUZZLE DALAM PEMBELAJARAN MATA DIKLAT WHOLE OF GOVERNMENT BAGI PESERTA PELATIHAN DASAR CALON PEGAWAI NEGERI SIPIL
}

Zaniar Aswandi
Badan Pengembangan Sumber Daya Manusia Provinsi Kalimantan Barat
zan_aswandi@ @ahoo.com

Diterima: Februari 2020; Direvisi: Maret 2020; Disetujui: April 2020

\begin{abstract}
Delivering training subjects by using game is supposed to affect the result of study and create fun situation. This research tried to answer a problem question whether the using of a puzzle game makes a difference in the result of study between the experiment group and the control group in the delivery of training subject Whole of Government. This was a mixed-method research using quasi experiment method and documentary study. There were two populations in this research, coming from 2 classes of Basic Training for Probationary Civil Servant (Latsar CPNS) organized in the Agency of Human Resources Development of West Kalimantan Province. Data were gained by using test and photo documents. The result of the hypothesis test by using a t-test for independent samples accepted the null hypothesis, meaning that there was no significant difference in the result of study delivery between experiment class and control class. On the other hand, based on the review of the photo documentation, it is seen that trainees were active and enthusiastic about the game so that it can be concluded that puzzle game created fun atmosphere.
\end{abstract}

\section{Keyword: latsar cpns, puzzle game, quasi experiment, WoG.}

Abstraksi. Penyampaian materi pembelajaran menggunakan permainan diduga dapat mempengaruhi hasil belajar dan menciptakan suasana yang menyenangkan. Tujuan penelitian ini adalah menganalisis perbedaan hasil belajar Whole of Government antara kelas yang menggunakan permainan puzzle dengan yang tidak. Penelitian ini menggunakan metode campuran yaitu quasi eksperimen untuk menguji hipotesis dan studi dokumen untuk mengkaji suasana pembelajaran. Ada dua populasi yang diteliti, yang berasal dari 2 angkatan Pelatihan Dasar Calon Pegawai Negeri Sipil (Latsar CPNS) yang diselenggarakan oleh Badan Pengembangan Sumber Daya Manusia Provinsi Kalimantan Barat. Data diperoleh dengan menggunakan instrumen test dan dokumentasi foto. Hasil dari uji hipotesis komparasi dengan menggunakan uji $t$ untuk sampel independen menerima hipotesis nol yang berarti bahwa tidak ada perbedaan signifikan dalam hasil belajar antara kelas eksperimen dan kelas kontrol.

Kata kunci: pelatihan dasar cpns, permainan puzzle, quasi experiment, whole of government.

\section{PENDAHULUAN}

Pembelajaran yang efektif dan efisien akan terwujud apabila pengajar menerapkan metode pembelajaran yang tepat untuk mengimplementasikan strategi pembelajaran yang telah dituangkan dalam rencana ke dalam bentuk kegiatan nyata dan praktis. Apabila strategi merupakan pola umum dalam suatu pembelajaran, maka metode merupakan cara yang digunakan oleh tenaga pengajar untuk mencapai tujuan pembelajaran yang ditetapkan (Suprapti, 2016). 
Berdasarkan hasil penelitian Nasution (2017), berbagai macam metode pembelajaran yang digunakan dapat menunjukkan hasil belajar yang optimal, sepanjang metode yang dipilih tersebut tepat dan sesuai dengan kebutuhan siswa. Dalam konteks pelatihan bagi calon Pegawai Negeri Sipil, Peraturan Lembaga Administrasi Negara Nomor 12 Tahun 2018 tentang Pelatihan Dasar Calon Pegawai Negeri Sipil menekankan agar proses pembelajaran tidak hanya mengandalkan kepada metode ceramah. Hal ini dikaitkan dengan kondisi kekinian yang lebih menuntut adanya proses belajar yang inovatif serta karakter peserta pelatihan yang merupakan orang-orang yang telah dewasa.

Penelitian tentang penggunaan metode permainan dalam pembelajaran telah banyak dilakukan dan pada umumnya menunjukkan korelasi positif antara penggunaan metode permainan terhadap hasil belajar. Di antaranya, penelitian Khudori dkk. (2012) yang menunjukkan bahwa games ular tangga dan puzzle samasama dapat meningkatkan prestasi belajar, Harefa (2014) yang menunjukkan bahwa penggunaan permainan dapat meningkatkan hasil belajar matematika, serta Machin (2012) yang membuktikan pengaruh positif permainan call cards terhadap hasil belajar mata pelajaran Biologi.

Dalam konteks pelatihan bagi Aparatur Sipil Negara (ASN), penelitian tentang penggunaan permainan dalam pembelajaran masih terbatas. Salah satu yang pernah dilakukan adalah oleh Suharsono (2015) yang meneliti tentang penggunaan permainan sundamanda pelatihan teknis. Penelitian tentang penggunaan metode pembelajaran dalam pelatihan pegawai menjadi perlu untuk dilakukan karena karakter pembelajar yang berbeda dibandingkan dengan pelajar sekolah atau mahasiswa yang telah sering diteliti. Hal ini juga sejalan dengan amanat Peraturan LAN RI Noor 12 Tahun 2018 sebagaimana dikemukakan di atas, bahwa proses pembelajaran hendaknya inovatif agar pesan yang disampaikan oleh pengajar (widyaiswara) dapat diterima dengan baik oleh para peserta.

Di dalam proses pembelajaran, permainan digunakan sebagai media untuk menyampaikan pesan dari widyaiswara (berupa materi pelatihan) kepada para peserta pelatihan. Hal ini diharapkan dapat membangkitkan minat untuk belajar, membantu mengingat materi, menggambarkan bentuk konkret dari materi dari konsep abstrak, dan melihat hubungan antara materi dengan alam sekitarnya (Muhammad, 2012). Dengan demikian, penggunaan permainan dipercaya dapat membuat proses pembelajaran menjadi efektif.

Selain pertimbangan efektivitas, penggunaan permainan juga dapat menciptakan suasana pembelajaran yang yang menyenangkan. Suasana belajar yang menyenangkan ini dipercaya mampu mengusir kejenuhan sehingga siswa atau peserta pembelajaran mampu meraih prestasi yang diharapkan (Permatasari, et al, 2014). Selain itu juga membuat peserta antusias untuk mempelajari materi sehingga terbentuk minat belajar yang mendukung pengembangan potensi dirinya (Wulandari, 2016).

Penggunaan permainan puzzle pada orang dewasa dapat digunakan untuk mengasah kemampuan berpikir, kecepatan pikiran dan tangan, melatih kesabaran, serta kemampuan untuk berbagi (Dewi, 2016). Manfaat-manfaat ini kiranya sejalan dengan prinsip mata diklat Whole of Government sebagai subyek penelitian ini yang 
menekankan pada kolaborasi dan koordinasi untuk mengatasi permasalahan yang kompleks (Christensen \& Laegreid, 2007). Penggunaan permainan puzzle jug diharapkan dapat mencairkan suasana sehingga peserta merasa betah dengan pembelajaran. Dengan demikian, permainan ini diharapkan akan membantu pemahaman peserta mengenai materi mata diklat Whole of Government.

Memperhatikan rumusan tujuan pembelajaran dan hasil belajar mata diklat Whole of Government sebagaimana tercantum di dalam modul pelatihan (Suwarno \& Sejati, 2017), terdapat katakata kunci yaitu "menjelaskan" dan "menganalisis". Di dalam Taksonomi Bloom yang telah direvisi, kata-kata kunci tersebut menunjukkan bahwa hasil pembelajaran berada pada ranah proses kognitif (Widodo, 2005). Untuk mengetahui perkembangan kognitif peserta pelatihan, maka salah satu metode yang dapat digunakan adalah pre-test dan posttest (Effendy, 2016). Melalui metode ini, dilakukan perbandingan antara kondisi sebelum materi disampaikan dan kondisi sesudahnya.

Oleh karena itu, penelitian ini bertujuan untuk mengetahui apakah terdapat perbedaan hasil pembelajaran mata diklat Whole of Government antara kelas yang menggunakan permainan puzzle dengan kelas yang tidak menggunakan permainan tersebut, serta apakah permainan puzzle dapat menciptakan suasana yang menyenangkan dalam pembelajaran Whole of Government. Penelitian ini diharapkan dapat memberikan manfaat teoritis dengan menyediakan referensi bagi penelitian selanjutnya mengenai penggunaan metode permainan dalam pembelajaran, khususnya dalam pelatihan bagi ASN. Adapun manfaat praktis yang diharapkan adalah untuk memberikan gambaran dan berbagi pengalaman tentang penggunaan permainan dalam pembelajaran mata pelatihan.

Berdasarkan tujuan penelitian, maka hipotesis dari penelitian ini adalah "Terdapat perbedaan hasil pembelajaran mata diklat Whole of Government antara kelas yang menggunakan permainan puzzle dan kelas yang tidak menggunakan permainan puzzle". Selain itu, penelitian ini juga akan membuktikan apakah suasana belajar yang menyenangkan dapat diciptakan dengan penggunaan permainan puzzle.

\section{METODE PENELITIAN}

Penelitian ini bermaksud untuk mengetahui hasil dari penerapan perlakuan yang berbeda terhadap obyek penelitian. Sesuai tujuan penelitian, maka metode penelitian yang digunakan adalah mixedmethod antara metode quasi experiment dan metode deskriptif. Pendekatan yang dilakukan juga campuran di mana metode quasi experiment menggunakan pendekatan kuantitatif sedangkan metode deskriptif menggunakan pendekatan kualitatif.

Populasi dalam penelitian ini adalah peserta Pelatihan Dasar CPNS Golongan III yang diselenggarakan di Badan Pengembangan Sumber Daya Manusia Provinsi Kalimantan Barat. Jumlah populasinya adalah 2 kelas yang masingmasing berjumlah 41 peserta. Kelas peserta dibedakan menjadi kelas eksperimen dan kelas kontrol. Populasi ini dianggap homogen dengan kriteria pangkat, jabatan serta mengikuti jenis pelatihan yang sama. Karena karakteristik populasinya homogen dan jumlahnya tidak terlalu besar, maka penelitian ini menggunakan sampel jenuh yaitu keseluruhan populasi menjadi sampel.

Pengumpulan data dilakukan pada tanggal 12 Oktober 2019 untuk kelas pada 
peserta dari Angkatan LXIV yang menjadi kelas eksperimen dan pada tanggal 14 Oktober 2019 pada Angkatan LXV sebagai kelas kontrol. Instrumen yang digunakan adalah pre-test dan post-test untuk mengetahui kondisi sebelum dan sesudah pembelajaran, yang digunakan untuk uji hipotesis dan dokumentasi kegiatan pembelajaran.

Teknik analisis data dilakukan dengan dua metode, yaitu perhitungan statistik untuk pengujian hipotesis dan studi dokumentasi untuk menjelaskan suasana pembelajaran. Data yang terkumpul diuji validitasnya dengan menggunakan skala Product Momen Pearson melalui aplikasi SPSS. Uji ini dilakukan terhadap data hasil pre-test dan post-test pada masing-masing kelas. Pengukuran data pada masingmasing kelas ini disebut juga analisis data berpasangan karena muncul pada unit eksperimental yang sama dengan variabel yang sama namun pada waktu yang berbeda (Effendy, 2016). Pengujian reliabilitas data dilakukan dengan pengukuran Cronbach Alpha. Selanjutnya, efek kausal penggunaan permainan puzzle diukur dengan melihat perbedaan antara selisih post-test dan pre-test pada kelompok eksperimen dan kelompok kontrol. Pengukuran ini dilakukan melalui t-test untuk sampel independen.

Suasana pembelajaran dalam penerapan permainan puzzle dijelaskan melalui analisis terhadap dokumentasi pelaksanaan kegiatan. Dalam hal ini, penulis mengadaptasi analisis semiotika Barthes (Enrieco \& Herry, 2019) untuk memaknai peristiwa dalam suatu dokumentasi melalui tahapan denotasi dan konotasi. Mengingat analisis data lebih bertujuan untuk mengungkap makna dari gambar, maka dalam penelitian ini, pemaknaan tahapan konotasi hanya akan mengulas aspek Trick Effect dan Pose karena aspek-aspek lain lebih mengarah kepada kualitas fotografi.

\section{HASIL DAN PEMBAHASAN}

a. Hasil

Berdasarkan hasil uji validitas. dengan menggunakan skala Pearsons Product Moment dengan aplikasi SPSS didapatkan hasil bahwa instrumen yang digunakan adalah valid. Hal tersebut dapat dilihat pada tabel di bawah ini:

Tabel 1

Hasil Uji Validitas Instrumen

\section{Correlations}

\begin{tabular}{llrr}
\hline & & Pretest & \multicolumn{1}{c}{ Posttest } \\
\hline \multirow{4}{*}{ Pretest } & Pearson & 1 & $.586^{* *}$ \\
& Correlation & & \\
& Sig. (2-tailed) & & .000 \\
& N & 41 & 41 \\
& Pearson & $.586^{* *}$ & 1 \\
& Correlation & & \\
Posttest & Sig. (2-tailed) & .000 & \\
& N & 41 & 41 \\
\hline
\end{tabular}


Hasil uji validitas instrumen Hasil Uji reliabilitas dengan instrumen menunjukkan angka $r$ hitung sebesar. 0,586 Cronbach Alpha menunjukkan nilai 0,720, pada skala Pearson Correlation, lebih besar lebih tinggi dari standar 0,70. sehingga dari $r$ tabel yaitu 0,561. Tingkat instrumen yang digunakan dapat dikatakan kepercayaan pada perhitungan ini adalah sebagai instrumen yang reliabel. Hasil $99 \%$. dimaksud dapat dilihat pada tabel berikut:

Hasil uji reliabilitas menunjukkan bahwa instrumen yang digunakan juga reliabel.

Tabel 2

Hasil Uji Reliabilitas

\section{Case Processing Summary}

\begin{tabular}{llrr}
\hline & & $\mathrm{N}$ & $\%$ \\
\hline \multirow{4}{*}{ Cases } & Valid & 41 & 100.0 \\
& Excluded $^{\mathrm{a}}$ & 0 & .0 \\
& Total & 41 & 100.0 \\
\hline
\end{tabular}

$\frac{\text { Reliability Statistics }}{\text { Cronbach's N of Items }}$
Alpha

Data yang digunakan juga terdistribusi normal. Pengujian terhadap distribusi data menggunakan Uji Normalitas Liliefors (Kolmogorov-Smirnov) dan Uji Normalitas Shapiro-Wilk dengan menggunakan prosedur SPSS Explore. Berikut adalah hasil uji normalitas untuk data yang berasal dari kelompok kontrol (1) dan kelompok eksperimen (2):

Tabel 3

Hasil Uji Normalitas

Tests of Normality

\begin{tabular}{llcccrrrr}
\hline & \multirow{2}{*}{ KELAS } & \multicolumn{3}{c}{ Kolmogorov-Smirnov $^{\mathrm{a}}$} & \multicolumn{4}{c}{ Shapiro-Wilk } \\
& & Statistic & df & Sig. & Statistic & df & Sig. \\
\hline \multirow{2}{*}{ MEAN } & 1 & .121 & 41 & .135 & .963 & 41 & .202 \\
& 2 & .133 & 41 & .064 & .967 & 41 & .274 \\
\hline
\end{tabular}

Dari hasil di atas, terlihat bahwa selisih rerata untuk kelas kontrol dan kelas eksperimen dalam Uji Normalitas Liliefors (Kolmogorov-Smirnov) menunjukkan angka signifikansi masing-masing sebesar 0,135 dan 0,64. Angka signifikansi yang lebih besar dari $=0,05$ menunjukkan bahwa data populasi telah terdistribusi secara normal.

Selanjutnya, pengujian terhadap hipotesis dilakukan dengan menguji efek 
kausal antar kelompok, yaitu selisih hasil post-test dan pre-test pada kelompok eksperimen dan kelompok kontrol. ini: Pengujian ini dilakukan melalui t-test untuk

Tabel 4

Hasil t-Test Sampel Independen

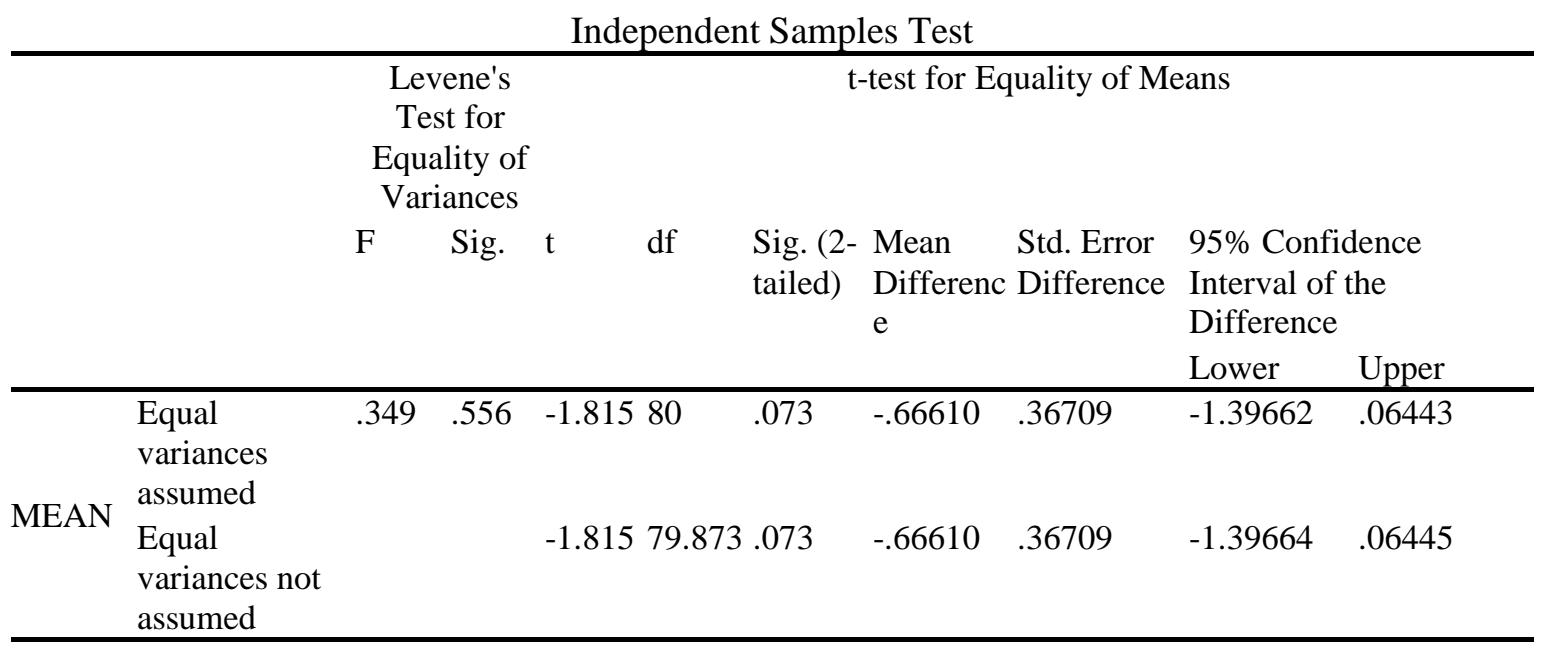

Pada tabel di atas ternyata hasil perhitungan menunjukkan $p$-value (2 tailed) sebesar 0,073 atau lebih besar dari 0,05 yang berarti bahwa Hipotesis $\mathrm{Nol}\left(\mathrm{H}_{0}\right)$ diterima dan Hipotesis Kerja $\left(\mathrm{H}_{\mathrm{a}}\right)$ ditolak. Dengan demikian, tidak ada perbedaan yang signifikan dalam hasil belajar mata diklat Whole of Government antara kelas yang menggunakan permainan puzzle dengan kelas yang tidak menggunakan permainan puzzle.

Terkait dengan masalah suasana pembelajaran, telah dibuat beberapa dokumentasi foto yang dapat menggambarkan berlangsungnya suasana pembelajaran dengan menggunakan permainan puzzle. Peserta dibagi ke dalam 6 kelompok yang diberi tugas untuk menyusun kepingan puzzle berisikan ringkasan materi Whole of Government. Selanjutnya, masing-masing kelompok sampel independen. Dari hasil pengukuran, didapat hasil sebagaimana tabel di bawah 
Tabel 5

Rerata Hasil Pre-test dan Post-test Kelas Kontrol dan Kelas Eksperimen

\begin{tabular}{|l|c|c|c|}
\hline \multicolumn{1}{|c|}{ KELAS } & PRETEST & POSTTEST & SELISIH \\
\hline KONTROL & 3,76 & 5,94 & 2,17 \\
\hline EKSPERIMEN & 3,95 & 6,57 & 2,62 \\
\hline
\end{tabular}

Berdasarkan tabel di atas, nilai rata-rata dan selisih hasil pre-test dan post-tes pada kelas eksperimen lebih tinggi dibandingkan dengan kelas kontrol sehingga secara sederhana dapat dilihat bahwa hasil belajar pada kelas eksperimen lebih baik dibandingkan dengan kelas kontrol. Namun, hasil uji hipotesis komparasi menunjukkan bahwa tidak ada perbedaan yang signifikan dalam hasil belajar antara kedua kelas tersebut. Pada umumnya, berbagai penelitian menunjukkan bahwa penggunaan permainan memberikan pengaruh positif terhadap hasil belajar, misalnya penelitian oleh Khudori (2012), Harefa, (2014) dan Machin (2012).

Hasil yang berbeda ditunjukkan oleh penelitian Suharsono (2015). Dalam Pembelajaran Kompetensi Non Teknis Planning and Organizing Pegawai Direktorat Jenderal Pajak yang menggunakan permainan Sundamanda ternyata tidak membuat semua indikator perilaku kompetensi dapat dipahami oleh peserta meskipun terjadi peningkatan pemahaman. Namun di sisi lain, hampir semua peserta memberikan respon yang positif terhadap penggunaan permainan dalam pembelajaran dimaksud.

Temuan dalam penelitian Suharsono di atas kiranya hampir serupa dengan penelitian ini bahwa penggunaan permainan sebagai metode dalam pembelajaran pelatihan bagi ASN belum menunjukkan hasil yang signifikan. Tidak signifikannya perbedaan antara kedua populasi sebagai hasil dari penelitian ini tidak dapat diartikan bahwa penggunaan permainan sebagai metode pembelajaran tidak bermanfaat terhadap hasil belajar. Mengingat masih sangat terbatasnya penelitian tentang penggunaan permainan dalam pembelajaran pelatihan bagi ASN, maka untuk menyimpulkan mengenai hubungan antara penggunaan permainan sebagaimana dimaksud dengan hasil belajar masih perlu dibuktikan dengan penelitian-penelitian selanjutnya.

Penggunaan metode dalam pembelajaran merupakan salah satu sub faktor eksternal yang mempengaruhi hasil belajar (Slameto, 2019). Dengan demikian upaya pencapaian tujuan pembelajaran yang efektif tentunya juga harus mempertimbangkan faktor-faktor internal maupun eksternal lainnya. Metode pembelajaran yang menarik tentunya akan memberikan dampak yang positif terhadap hasil belajar apabila kondisi pada faktorfaktor penentu lainnya juga mendukung.

Selain mencapai hasil belajar yang ditunjukkan melalui nilai tes, proses pembelajaran juga hendaknya dilakukan dalam suasana yang menyenangkan. Berdasarkan foto-foto dokumentasi dalam penelitian ini, suasana menyenangkan juga tercipta dalam kegiatan pembelajaran dengan menggunakan permainan puzzle. Hal tersebut dapat diamati melalui foto dokumentasi kegiatan pada Gambar 1 dan Gambar 2. 


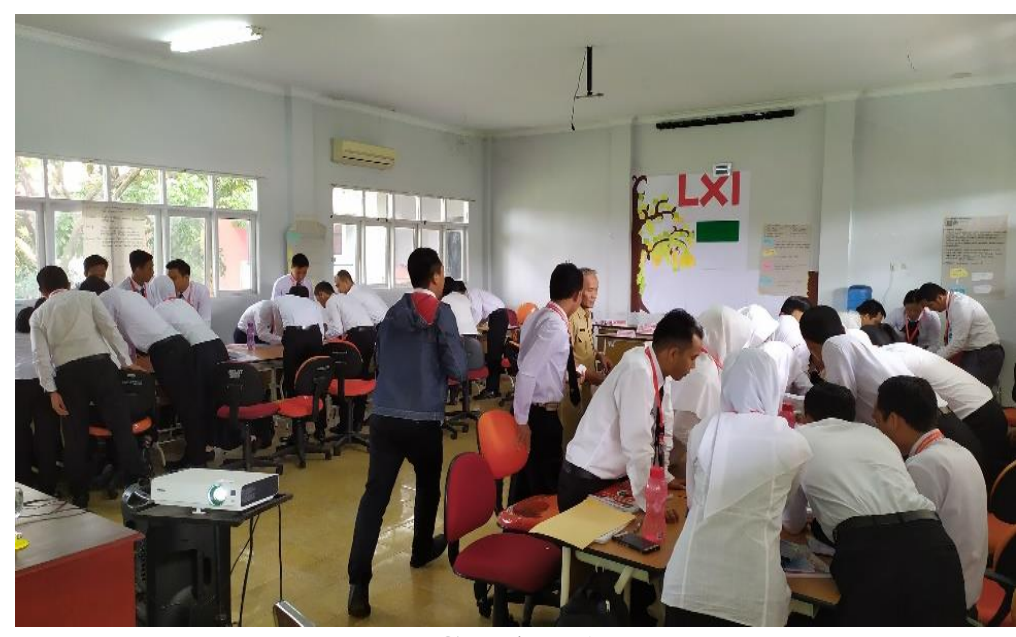

Gambar 1

Foto Kegiatan

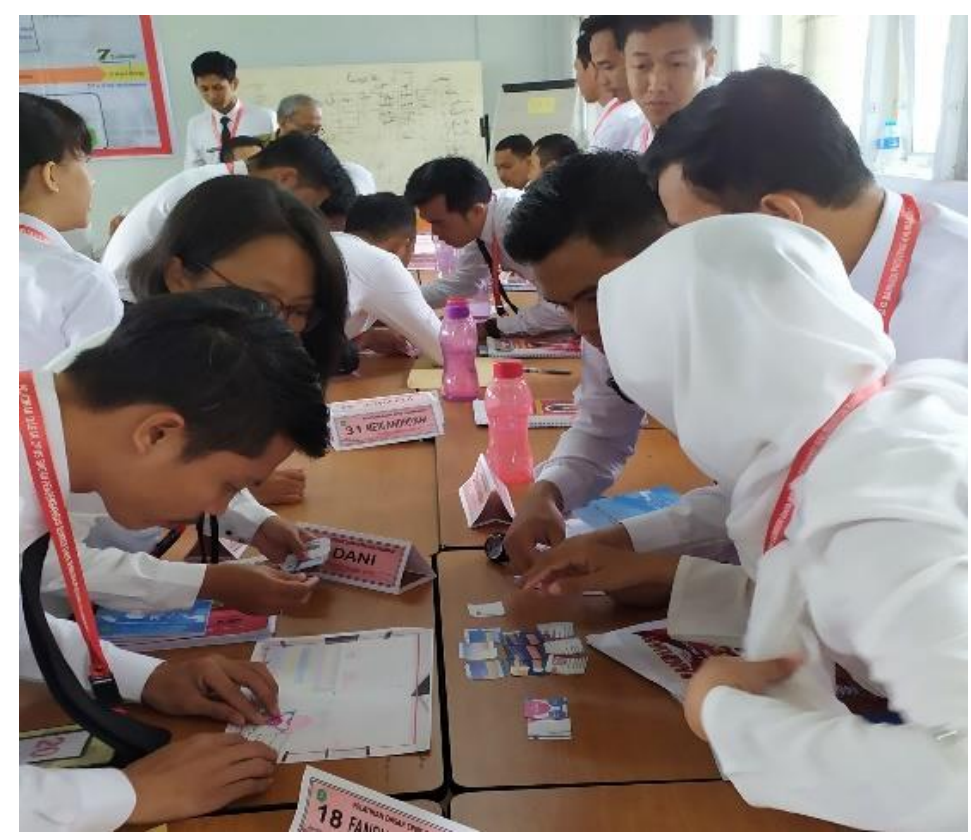

Gambar 2

Foto Kegiatan

Berdasarkan Gambar 1, penjelasan yang dapat diberikan pada tahap denotasi adalah suasana kelas Pelatihan Dasar CPNS dengan para peserta yang berseragam putih hitam sedang melakukan aktivitas permainan menyusun puzzle. Sebagian besar peserta terlihat mengelilingi meja panjang dengan posisi tubuh menunduk layaknya sedang mengerjakan sesuatu. Ada pula peserta yang terlihat sedang bergerak berpindah tempat.
Untuk penjelasan tahap konotasi, dari aspek Trick Effect tidak ada rekayasa dalam pengambilan Gambar 1. Suasana kelas diambil tanpa pemberitahuan terlebih dahulu atau pengaturan oleh pengambil gambar sehingga suasana yang terekam adalah apa adanya. Dengan demikian hal yang diinformasikan adalah kondisi yang sebenarnya.

Dari aspek Pose, terlihat para peserta memang sedang melakukan aktivitas bersama yang melibatkan seluruh anggota 
kelas. Gesture peserta yang tertangkap dalam foto tersebut menunjukkan bahwa mereka aktif dalam kegiatan dan tidak ada yang terasing dari kegiatan kelas.

Penjelasan mengenai Tahap Denotasi pada Gambar 2 adalah peserta dalam satu kelompok yang sedang menyusun kepingan puzzle. Di kejauhan terlihat peserta dari kelompok yang lain juga sedang melakukan aktivitas yang sama.

Aspek Trick Effect pada Tahap Konotasi dalam Gambar 2 menunjukkan tidak ada pengarahan khusus kepada peserta. Apa yang dapat ditangkap dari gambar adalah kondisi yang senyatanya di kelas pada waktu pembelajaran. Ekspresi wajah peserta tertangkap kamera tanpa disadari oleh mereka.

Pada aspek Pose, Gambar 2 menampilkan citra dalam lingkup yang lebih kecil dibandingkan Gambar 1 sehingga ekspresi beberapa orang peserta dapat dilihat dengan lebih jelas. Pada gambar dimaksud, terlihat raut wajah yang serius namun tidak terkesan tegang. Posisi tangan dan pose tubuh yang tercitrakan dalam foto menunjukkan bahwa para peserta menunjukkan minat dan aktif melakukan permainan.

Analisis semiotika terhadap foto-foto kegiatan menunjukkan bahwa penggunaan permainan puzzle telah menciptakan suasana yang menyenangkan dalam pembelajaran. Meskipun hasil uji statistik tidak menunjukkan perbedaan yang signifikan dalam hasil belajar, namun suasana belajar yang menyenangkan kiranya juga merupakan hal yang positif dari penerapan permainan dalam pembelajaran.

\section{SIMPULAN}

Pemanfaatan permainan puzzle merupakan salah satu upaya untuk menciptakan proses pembelajaran yang menarik dan diharapkan dapat memberikan pengaruh terhadap hasil pembelajaran. Namun, berdasarkan hasil uji $\mathrm{t}$ sampel independen menunjukkan perbedaan antara kelas yang menggunakan permainan puzzle dengan yang tidak ternyata tidak signifikan (hipotesis kerja ditolak), meskipun dari data rerata sederhana terlihat bahwa hasil post test pada kelas eksperimen lebih tinggi daripada kelas kontrol.

Berdasarkan analisis semiotik terhadap foto-foto dokumentasi kegiatan terlihat bahwa foto-foto dimaksud menunjukkan suasana kelas yang apa adanya dan merekam kondisi kelas dan kegiatan para peserta. Dari aspek penciptaan suasana, dapat disimpulkan bahwa permainan puzzle dapat menciptakan suasana yang menyenangkan dalam pembelajaran.

Meskipun hipotesis ditolak, namun secara umum penelitian ini dapat menunjukkan manfaat penggunaan permainan puzzle dalam pembelajaran Whole of Government. Untuk mendapatkan gambaran yang lebih tajam dan mendalam, kiranya perlu dilakukan penelitian lanjutan terutama dengan memasukkan faktor-faktor lain sebagai variabel yang ikut diperhitungkan dalam analisis data kuantitatif. Akan lebih baik lagi jika dapat diteliti pemahaman peserta mengenai prinsip-prinsip Whole of Government setelah pelatihan selesai dilaksanakan. 


\section{DAFTAR PUSTAKA}

Christensen, T., \& Laegreid, P. (2007). The Whole of Government Approach to Public Sector Reform. Public Administration Review, 67(6), 1059-1066.

Dewi, R. S. (2016). Pengaruh Senam Otak dan Bermain Puzzle terhadap Fungsi Kognitif Lansia di PLTU Jember. Jurnal Kesehatan Primer, 1(1), 64-69.

Effendy, I. (2016). Pengaruh Pemberian Pre-Test dan Post-Test terhadap Hasil Belajar Mata DiklaT HDW.DEV.100.2.A pada Siswa SMK Negeri 2 Lubuk Basung. VOLT: Jurnal Ilmiah Pendidikan Teknik Elektro, 1(2), 81-88.

Enrieco, E., \& Herry. (2019). Analisis Human Interest pada Pameran Foto Karya Mahasiswa Fakultas Ilmu Komunikasi dan Bahsa UBSI. Komunika: Journal of Communication Science and Islamic Da'wah, 3(1), 214-225.

Harefa, A. O. (2014). Pembelajaran dengan Menggunakan Metode Permainan pada Sekolah Menengah Pertama. Dinamika, XII(2), 288-297.

Ibrahim. (2017). Perpaduan Model Pembelajaran Aktif Konvensional (Ceramah) dengan Cooperatif (Make- A Match) untuk Meningkatkan Hasil Belajar Pendidikan Kewarganegaraan. Suara Guru : Jurnal Ilmu Pendidikan Sosial, sains, dan Humaniora, 3(2), 199-211.

Khudori, M., Ashadi, \& Masykuri, M. (2012). Pembelajaran IPA dengan Metode TGT Menggunakan Media Games Ular Tangga dan Puzzle Ditinjau dari Gaya Belajar dan Kreativitas Siswa. Jurnal InKuiri, 1(2), 154-162. Diambil kembali dari http://jurnal.pasca.uns.ac.id

Machin, A. (2012). Pengaruh Permainan Call Cards terhadap Hasil Belajar dan Aktivitas Pembelajaran Biologi. Jurnal Pendidikan IPA Indonesia, 1(2), 163-167.

Muhammad, R. (2012). Penggunaan Animasi dengan Macromedia Flash Untuk Meningkatkan Daya Ingat terhadap Matematika pada Materi Geometri di Kelas X SMA Negeri 3 Banda Aceh. Didaktika, XII(2), 199-215.

Nasution, K. M. (2017). Penggunaan Metode Pembelajaran Dalam Peningkatan Hasil Belajar Siswa. Studia Didaktika: Jurnal Ilmiah Bidang Pendidikan, 11(1), 9-16.

Permatasari, A. I., Mulyani, B., \& Nurhayati, N. D. (2014). Efektivitas Penggunaan Model Pembelajaran Joyful Learning dengan Metode Pemberian Tugas terhadap Prestasi Belajar Siswa pada Materi Pokok Koloid Siswa Kelas XI IPA SMA Negeri 1 Simo Tahun Pelajaran 2012/2013. Jurnal Pendidikan Kimia (JPK), 3(1), 117-122.

Slameto. (2019). Belajar dan Faktor-Faktor yang Mempengaruhi. Jakarta: Rineka Cipta.

Suharsono, A. (2015). Pengembangan Metode Pembelajaran Kompetensi Non Teknis Planning and Organizing Pegawai Direktorat Jenderal Pajak dengan Permainan Sundamanda. Simposium Pendidikan Tahun 2015. Jakarta.

Suprapti, W. (2016). Ragam Strategi Diklat. Jakarta: Lembaga Administrasi Negara Republik Indonesia.

Suwarno, Y., \& Sejati, T. A. (2017). Whole of Government : Modul Pelatihan Dasar Calon PNS. Jakarta: Lembaga Administrasi Negara Republik Indonesia.

Widodo, A. (2005). Taksonomi Tujuan Pembelajaran. Didaktis, 4(2), 61-69.

Wulandari, D. (2016). Model Pembelajaran yang Menyenangkan Berbasis Peminatan. Jurnal Inspirasi Pendidikan Universitas Kanjuruhan Malang, 6(2), 851-856. 